\title{
Parking Lot Optimization in Parallelogram Using the Concept Area of Rectangular and Right Triangle
}

\author{
Ihda Hasbiyati ${ }^{1}$, Widiawati Putri ${ }^{2}$, Arisman Adnan ${ }^{1}$, Ahriyati ${ }^{1}$, Hasriati ${ }^{1}$ \\ ${ }^{1}$ Department of Mathematics, University of Riau, Pekanbaru, Indonesia \\ ${ }^{2}$ Graduate School of Mathematics, University of Riau, Pekanbaru, Indonesia
}

Email address:

ihdahasbiyati@gmail.com (I. Hasbiyati),widiawati.putry@yahoo.com (W. Putri)

\section{To cite this article:}

Ihda Hasbiyati, Widiawati Putri, Arisman Adnan, Ahriyati, Hariati. Parking Lot Optimization in Parallelogram Using the Concept Area of Rectangular and Right Triangle. Pure and Applied Mathematics Journal. Vol. 8, No. 4, 2019, pp. 77-82. doi: 10.11648/j.pamj.20190804.12

Received: August 20, 2019; Accepted: September 19, 2019; Published: October 9, 2019

\begin{abstract}
Parking lots are one of the most important elements of transportation infrastructure. Parking lots with good design and the selection of suitable parking angles will provide optimal vehicle capacity. In this article, we will discuss the parking lot in the form of a Parallelogram with a broad concept of area, for parking a private car vehicle. In this paper, the land in the form of a jug is formed of two right and rectangular triangles. The method used is a linear program method that is formed from the broad concept of the area with the help of lindo software. The results obtained from this article are the forms of Parallelogram which are formed from two right triangles which are used divided into two parts, namely a right triangle with a base and a height of half a rectangle resulting in a total parking area of 873,600 square meters, with the number of car vehicles that can be parked on the inside of a parking lot with a 90 degree angle is as much as 520 car vehicles. So it can be concluded that the numbers formed from two right triangles and rectangles produce the optimal number of vehicles with a 90 degree parking angle.
\end{abstract}

Keywords: Linear Program, Parking Design, Parking Angle, Parking Capacity, Area

\section{Introduction}

Parking is a place to stop vehicles in the short and long term. Parking lots are one of the most important elements of transportation infrastructure. A good parking lot is a parking lot that has an optimal capacity. Factors that affect the optimal capacity in parking lots include the design of parking lots, parking angles, types of vehicles, and parking area. These factors provide a separate impact on parking lots, because if the design of parking lots with the right parking angle on a large parking area, will provide the capacity of certain types of vehicles optimally. Types of vehicles such as passenger cars, motorcycles, trucks, buses provide different sizes. Usually the parked vehicles will be separated according to the type of each vehicle. The way to park vehicles is different, there are those who park the parking capacity with a linear program, with parking spaces rectangular in 3 cases. Furthermore, Intan Syahrini and friends in 2018 discussed the mathematical model of parking lots for parking lots in the form of triangles, with the triangle shapes being discussed are equilateral triangles and isosceles triangles.

In this article the author is interested in discussing the optimization model for parking lots with different forms, namely the shape of the parking lot and vehicle in a straight line or usually referred to as parking with a 90 degree angle and parking illegally or called parking 30, 45, 60, and 75 degrees.

In 2019, Ihda Hasbiyati has begun research on transportation. Furthermore, Abdel Fatah and Taha in 2014 discussed the discussion with the broad concept of the area. The shape of the barn is divided into two parts, namely parallelogram formed from two right triangles with rectangles, and the length of a triangle formed from two right triangles with a square. Right triangle used is also divided into two parts, namely right triangle with base side and height is half of rectangle and right triangle with base side and height is half of square. So, this discussion is called optimization of long-distance parking lots with the concept of square area, rectangle and right triangle.

\section{Theoretical Background}




\subsection{Parking Area}

Parking lots are land used to park vehicles of certain types in the short and long term. Parking lots are not always in the land or on the road. There is a parking lot built in the building area such as under a building or inside a building. Each placement of parking lots or the selection of parking lots, each gives a good impact and also a bad impact, such as the ease of vehicles to get out or enter and the adverse effects that cause an accident. Parking lots made with the right land planning will provide more optimal capacity.

Parking lots have various forms such as square, rectangle, triangle, circle, rhombus, to irregular shape. The form of parking lot adjusts to the available land.

\subsection{Parking Design}

Parking design is a design of vehicle placement on parking lots. The design of the parking lot is very influential, because if the design is made improperly it will have a bad impact on the circulation of vehicles that are on the parking lot. A good design will produce an efficient, safe and optimal parking lot. Next is the general design of a rectangular parking lot.

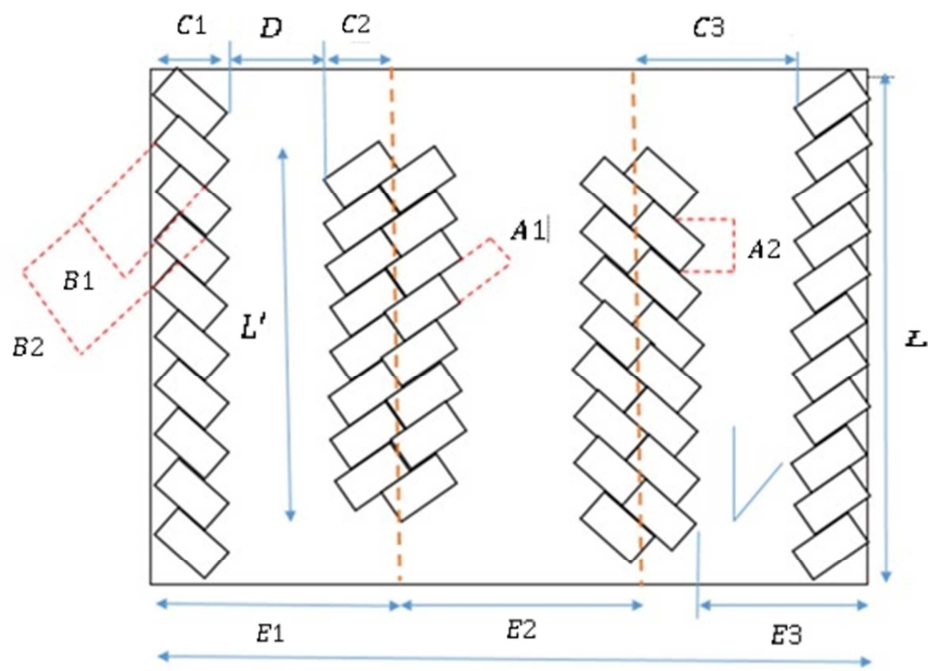

W

Figure 1. General design of a parking lot.

Description of Figure 1:

$\mathrm{A} 1=$ vehicle width

$\mathrm{A} 2=$ vehicle width when attacki ng

$\mathrm{B} 1=$ vehicle length

$\mathrm{B} 2=$ the length of the vehicle when it is attacking

$\mathrm{C} 1=$ vehicle length from wall to end of the vehicle

$\mathrm{C} 2=$ the length of the vehicle from the roadside to the end of the vehicle

$\mathrm{D}=$ length of road in the parking lot (entrance and exit of the vehicle)

$\mathrm{L}=$ land width

$L_{1}^{\prime}=$ the width of the first inner land

$L_{2}^{\prime}=$ the width of the second inner land

$\mathrm{W}=$ length of land

$\mathrm{E} 1=$ the length of the outer land

$\mathrm{E} 2=$ full length of the outer land

$\mathrm{E} 3=$ length of land inside

$X E \theta=$ the number of outer rows which are full of angles $\theta$

$X \theta=$ number of rows inside with angle $\theta$

$N \theta=$ number of vehicles inside with angle $\theta$

$N E \theta=$ the number of outer vehicles that are full of angles $\theta$

\subsection{Parking Angle}

Parking angle is a way of placing vehicles on parking lots. The methods used are usually of two types, namely straight and crooked. Parking by means of parking is a way of parking using angles of 30, 45, 60 and 75 degrees. While parking the vehicle in a straight way is by using a 90 degree angle.

\subsection{Type of Vehicle}

Along with the development of the times, the type of vehicle is increasing and the forms vary. In general, the types of vehicles in Indonesia that are usually parked are motorbikes, passenger cars, buses, trucks and others. The following is a measure of the parking space requirements for this type of car, which was taken from the Indonesian 
Ministry of Transportation.

Table 1. Optimization coefficient of parking lots for car vehicles.

\begin{tabular}{|c|c|c|c|c|c|c|}
\hline \multirow{2}{*}{ Dimension (meter) } & \multirow{2}{*}{ Symbol } & \multicolumn{5}{|l|}{ Angle } \\
\hline & & 30 & 45 & 60 & 75 & 90 \\
\hline Car width & $\mathrm{A} 1$ & 2.50 & 2.50 & 2.50 & 2.50 & 2.50 \\
\hline Line width when tilting & A2 & 5.00 & 3.54 & 2.89 & 2.59 & 2.50 \\
\hline Car length & B1 & 5.00 & 5.00 & 5.00 & 5.00 & 5.00 \\
\hline Line length when tilting & B2 & 9.33 & 7.50 & 6.44 & 5.67 & 5.00 \\
\hline $\begin{array}{l}\text { Parking line width from the wall to the } \\
\text { parking line boundary }\end{array}$ & $\mathrm{C} 1$ & 4.67 & 5.30 & 5.58 & 5.48 & 5.00 \\
\hline Middle parking line width & $\mathrm{C} 2$ & 3.58 & 4.42 & 4.96 & 5.15 & 5.00 \\
\hline The width of the alley & $\mathrm{D}$ & 3.50 & 3.75 & 4.50 & 6.00 & 5.00 \\
\hline Full exterior width & E1 & 11.75 & 13.47 & 15.04 & 16.63 & 17.00 \\
\hline Exterior width & E2 & 8.17 & 9.05 & 10.08 & 11.48 & 12.00 \\
\hline Interior width & E3 & 7.08 & 8.17 & 9.46 & 11.15 & 12.00 \\
\hline
\end{tabular}

\section{Materials}

\subsection{Linear Program}

A linear program is a mathematical method used to allocate resources with given limits to achieve a goal that is maximizing profits and minimizing costs. Mathematical programs are widely applied in daily life as applied in economic, industrial, military, social and other problems. The linear program consists of a mathematical model with an objective function and several linear constraints. Linear programs have several characteristics including linearity, proportionality, additive, visibility and certainty. Formulation of problems in linear programs is to study problems by describing statements such as goals, limiting resources, alternative possible decisions, time limits for decisionmaking, relationships between the parts studied and others. Setting goals is the most important aspect, because the goal is a form that aims to optimize.

Completion of linear programs can be done using several ways, namely by using graphics and simplistic methods. The graph method is a very simple method because the existing problems will be graphically illustrated. The graph method has a weakness, because it can only be used when the variable is not large than two. Next is the simplistic method, the method of completion by using the Gauss Jordan elimination technique with an iterative calculation. In addition to these two methods, quick completion can be done using computer software. Software that is often used is LINDO, LINGO, Excel Solver.

\subsection{Lindo}

LINDO or can be called Linear Interactive Discrete Optimizer is a software to solve linear programming problems with the working principle of entering data, completing and estimating the truth and feasibility of data based on its completion. Calculations on LINDO use the simplex method and to solve zero-integer linear programming problems with one software using the Branch and Bound method (Linus E. Schrage, 1986). There are some resistance to using LINDO, namely determining mathematical models according to the problem, determining the formulation and reading the results of reports that have been produced by LINDO (Mark Wiley, 2010).

\section{Result}

The mathematical model produced from this article is divided into 2 parts, namely:

1. The mathematical model of the shape of a parking lot is formed of rectangles and right triangles, where a right triangle with a base and a height is half of a rectangle.

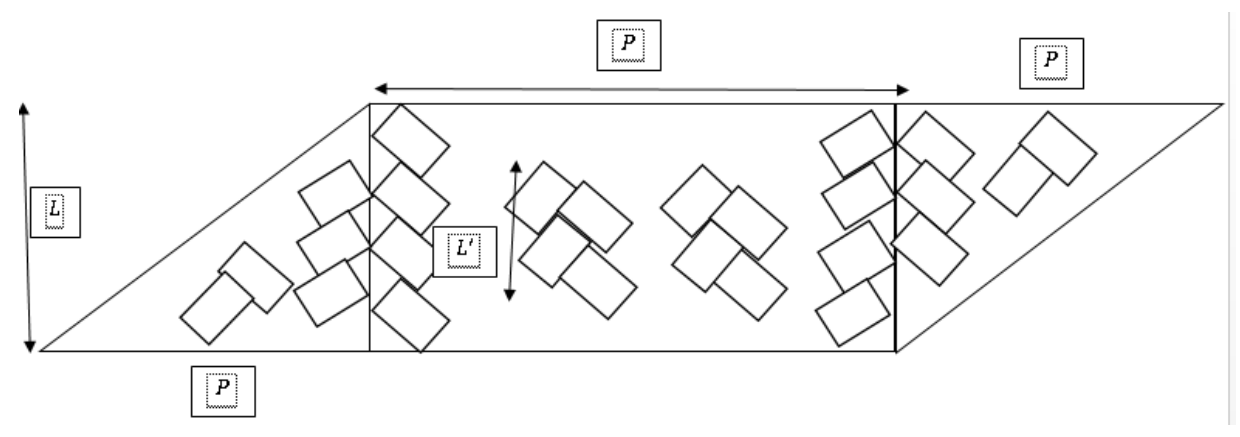

Figure 2. Design of parking spaces for parallelograms with right triangles (rectangles) and rectangles.

From Figure 1 and Figure 2, the area of the rectangular area is obtained as follows:

$$
\left(L-L^{\prime}\right) \cdot E 1
$$


and the area of a right triangle as follows:

$$
\frac{1}{2}(L \cdot E 3)
$$

$$
\begin{gathered}
\frac{1}{2}\left(L-L^{\prime}\right) \cdot E 1 \\
\frac{1}{2}(L \cdot E 2)
\end{gathered}
$$

Equations (1) to equation (6) are then summed according to the corresponding size so that an equation is formed which (5) is called the objective function as follows:

$$
\operatorname{Max} \mathrm{Z}=\sum_{\theta=30,45,60,75,90} 2\left(\left(\left(L-L^{\prime}\right) \cdot E 1\right) N E \theta+(L \cdot E 2) N \theta+(L \cdot E 3) N E E \theta\right)
$$

Constraint:

$$
\begin{gathered}
E 1 X E \theta+E 2 X \theta+E 3 E \theta \leq P \\
A 2 N \theta-2 L^{\prime} X \theta \leq 0 \\
A 2 N E \theta-\left(L-L^{\prime}\right) X E \theta \leq 0 \\
A 2 N E E \theta-L E \theta \leq 0 \\
X E \theta+E \theta \leq 2 \\
E 1 X E \theta+E 2 X \theta+E 3 E \theta \leq P \\
\frac{1}{2}\left(A 2 N \theta-2 L^{\prime} X \theta\right) \leq 0 \\
\frac{1}{2}\left(A 2 N E \theta-\left(L-L^{\prime}\right) X E \theta\right) \leq 0
\end{gathered}
$$

$$
\begin{gathered}
\frac{1}{2}(A 2 N E E \theta-L E \theta) \leq 0 \\
E 1 X E \theta+E 2 X \theta+E 3 E \theta \leq P \\
\frac{1}{2}\left(A 2 N \theta-2 L^{\prime} X \theta\right) \leq 0 \\
\frac{1}{2}\left(A 2 N E \theta-\left(L-L^{\prime}\right) X E \theta\right) \leq 0 \\
\frac{1}{2}(A 2 N E E \theta-L E \theta) \leq 0 \\
X E \theta, X \theta, E \theta, N E \theta, N \theta, N E E \theta \geq 0
\end{gathered}
$$

2. The mathematical model of the form of parking lots is formed of rectangles and right triangles, where a right triangle with a base and a height is half of a square.

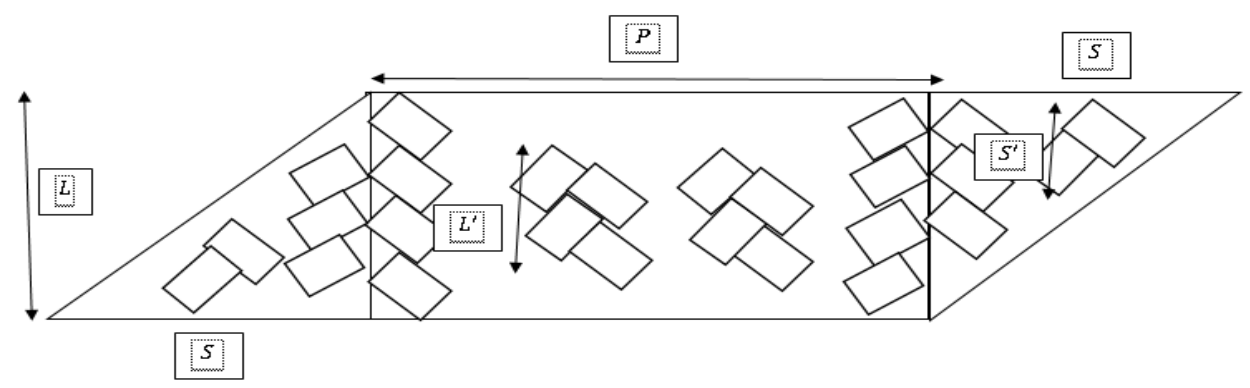

Figure 3. Design of parking spaces for parallelograms with right (square) and rectangular triangles.

Figure 1 and Figure 3, obtained by the area of a rectangle as follows:

$$
\begin{aligned}
& \left(L-L^{\prime}\right) \cdot E 1 \\
& (L \cdot E 2) \\
& (L \cdot E 3)
\end{aligned}
$$

and the area of a right triangle as follows:

$$
\begin{gathered}
\frac{1}{2}\left(S-S^{\prime}\right) \cdot E 1 \\
\frac{1}{2}(S \cdot E 2) \\
\frac{1}{2}(S \cdot E 3)
\end{gathered}
$$

Equations (9) to equation (12) are then summed according to the corresponding size so that an equation is formed which is called the objective function as follows:

$\operatorname{Max} \mathrm{Z}=\sum_{\theta=30,45,60,75,90}\left(\left(\left(\left(L-L^{\prime}\right) \cdot E 1\right)+\left(\left(S-S^{\prime}\right) \cdot E 1\right)\right) N E \theta+(L \cdot E 2)+(S \cdot E 2) N \theta+(L \cdot E 3)+(S \cdot E 3) N E E \theta\right)$

Constraint:

$$
\begin{gathered}
E 1 X E \theta+E 2 X \theta+E 3 E \theta \leq P \\
A 2 N \theta-2 L^{\prime} X \theta \leq 0 \\
A 2 N E \theta-\left(L-L^{\prime}\right) X E \theta \leq 0
\end{gathered}
$$

$$
\begin{gathered}
A 2 N E E \theta-L E \theta \leq 0 \\
X E \theta+E \theta \leq 2 \\
E 1 X E \theta+E 2 X \theta+E 3 E \theta \leq S \\
\frac{1}{2}\left(A 2 N \theta-2 S^{\prime} X \theta\right) \leq 0
\end{gathered}
$$




$$
\begin{gathered}
\frac{1}{2}\left(A 2 N E \theta-\left(S-S^{\prime}\right) X E \theta\right) \leq 0 \\
\frac{1}{2}(A 2 N E E \theta-S E \theta) \leq 0 \\
E 1 X E \theta+E 2 X \theta+E 3 E \theta \leq S \\
\frac{1}{2}\left(A 2 N \theta-2 S^{\prime} X \theta\right) \leq 0 \\
\frac{1}{2}\left(A 2 N E \theta-\left(S-S^{\prime}\right) X E \theta\right) \leq 0 \\
\frac{1}{2}(A 2 N E E \theta-S E \theta) \leq 0 \\
X E \theta, X \theta, E \theta, N E \theta, N \theta, N E E \theta \geq 0
\end{gathered}
$$

\section{Discussion}

In this section, we will discuss the calculations using LINDO software with the mathematical models obtained previously. The parking land coefficient in Table 1 is substituted into model 1 and model 2 that have been obtained. Furthermore, it is calculated using LINDO software. The following are the results of the LINDO calculation for both models with a rectangular area measuring $120 \times 70$ and a square land of $75 \times 75$.

1. The mathematical model of the shape of a parking lot is formed of rectangles and right triangles, where a right triangle with a base and a height is half of a rectangle.

LP Optimum Found at Step 16

Objective Function Value 1) 873600.0

$\begin{array}{ll}\text { VARIABLE } & \text { VALUE } \\ \text { NE30 } & 0.000000 \\ \text { NE45 } & 0.000000 \\ \text { NE60 } & 0.000000 \\ \text { NE75 } & 0.000000 \\ \text { NE90 } & 0.000000 \\ \text { N30 } & 0.000000 \\ \text { N45 } & 0.000000 \\ \text { N60 } & 0.000000 \\ \text { N75 } & 0.000000 \\ \text { N90 } & 520.000000 \\ \text { NEE30 } & 0.000000 \\ \text { NEE45 } & 0.000000 \\ \text { NEE60 } & 0.000000 \\ \text { NEE75 } & 0.000000 \\ \text { NEE90 } & 0.000000 \\ \text { XE30 } & 0.000000 \\ \text { XE45 } & 0.000000 \\ \text { XE60 } & 0.000000 \\ \text { XE75 } & 0.000000 \\ \text { XE90 } & 0.000000 \\ \text { X30 } & 0.000000 \\ \text { X45 } & 0.000000 \\ \text { X60 } & 0.000000\end{array}$

REDUCED COST
0.000000
0.000000
0.000000
0.000000
0.000000
0.000000
0.000000
0.000000
0.000000
0.000000
0.000000
0.000000
0.000000
0.000000
0.000000
85070.000000
97680.164062
109143.476562
120729.835938
123420.000000
32026.400391
20844.658203
10664.570312

$\begin{array}{lll}\text { VARIABLE } & \text { VALUE } & \text { REDUCED COST } \\ \text { X75 } & 0.000000 & 3127.518799 \\ \text { X90 } & 10.000000 & 0.000000 \\ \text { E30 } & 0.000000 & 37665.597656 \\ \text { E45 } & 0.000000 & 36860.085938 \\ \text { E60 } & 0.000000 & 36789.910156 \\ \text { E75 } & 0.000000 & 38982.804688 \\ \text { E90 } & 0.000000 & 40320.000000\end{array}$

\begin{tabular}{|c|c|c|}
\hline VARIABLE & VALUE & REDUCED COST \\
\hline NE30 & 0.000000 & 0.000000 \\
\hline NE45 & 0.000000 & 0.000000 \\
\hline NE60 & 0.000000 & 0.000000 \\
\hline NE75 & 0.000000 & 0.000000 \\
\hline NE90 & 0.000000 & 0.000000 \\
\hline N30 & 0.000000 & 0.000000 \\
\hline N45 & 0.000000 & 0.000000 \\
\hline N60 & 0.000000 & 0.000000 \\
\hline N75 & 0.000000 & 0.000000 \\
\hline N90 & 320.000000 & 0.000000 \\
\hline NEE30 & 0.000000 & 0.000000 \\
\hline NEE45 & 0.000000 & 0.000000 \\
\hline NEE60 & 0.000000 & 0.000000 \\
\hline NEE75 & 0.000000 & 0.000000 \\
\hline NEE90 & 0.000000 & 0.000000 \\
\hline XE30 & 0.000000 & 82832.500000 \\
\hline XE45 & 0.000000 & 99543.320312 \\
\hline XE60 & 0.000000 & 111145.617188 \\
\hline XE75 & 0.000000 & 122899.710938 \\
\hline XE90 & 0.000000 & 125630.000000 \\
\hline X30 & 0.000000 & 30800.900391 \\
\hline $\mathrm{X} 45$ & 0.000000 & 17882.189453 \\
\hline X60 & 0.000000 & 5988.009277 \\
\hline$X 75$ & 0.000000 & 0.000000 \\
\hline X90 & 6.250000 & 0.000000 \\
\hline E30 & 0.000000 & 37984.199219 \\
\hline $\mathrm{E} 45$ & 0.000000 & 36503.285156 \\
\hline E60 & 0.000000 & 35730.652344 \\
\hline E75 & 0.000000 & 37253.910156 \\
\hline E90 & 0.000000 & 38280.000000 \\
\hline
\end{tabular}

2. The mathematical model of the form of parking lots is formed of rectangles and right triangles, where a right triangle with a base and a height is half of a square.

LP Optimum Found at Step 2

Objective Function Value 1) 565500.0

\section{Conclusion}

From the results of the calculations obtained, it can be concluded that the parking area in the form of parallelogram is formed from two parts, namely parallelogram formed from two right triangles and rectangles. The right triangle used is divided into two parts, namely a right triangle with a base and a height of half of a rectangle resulting in a total parking area of 873,600 square meters with a number of inner vehicles 
with a 90 degree angle of 520 vehicles. Whereas a right triangle with a base and height is half of a long rectangle resulting in a total parking area of 565,500 square meters with a number of inner vehicles with a 90 degree angle of 320 car vehicles.

\section{References}

[1] A. S. Abdelfatah and M. A. Taha, Parking capacity optimization using linear programming, Journal of Traffic and Logistics Engineering, vol. 2, no. 3, 176-181, 2014.

[2] G. Chang, dan G. Ping, Research on parking space optimal design method in parking lots, International Journal of Advancements in Computing Technology (IJACT), 5 (2013), 79-85.

[3] Director General of Indonesian Land Transportation, 1996, Organizing Parking Facilities (Jakarta: Department of Transportation).

[4] I. Hasibyati, Analysis of Multi-Stage Stochastic Optimization Model for Stochastic Transportation Problem, Journal of Transportatiob Systems, 4 (2019), 21-25.

[5] F. S. Hillier dan G. J. Lieberman, Introduction to Operations Research, Tenth Edition, McGraw-Hill, New York, 2010.

[6] S. Munzir, M. Ikhsan, dan Z. Amin, Linear programming for parking slot optimization: a case study at Jl. T. Panglima Polem Banda Aceh, Prosiding 6th IMT-GT Conference on Mathematics, Statistics and its Applications (ICMSA 2010)
Universiti Tunku Abdul Rahman, Kuala Lumpur, Malaysia, 2010 .

[7] M. Ramli, D. Puspitasari, dan V. Hanafi, Optimization model of parking charge and Income using lagrange multiplier method, Prosiding AIP Conference Series, pp. 030034-1 030034-8.

[8] N. K. Oladejo dan B. D. Awuley, Application of linear programming in optimization of parking slot: a case study of Tamale-Bolgatanga lorry station in Ghana, International Journal of Emerging Technology and Advanced Engineering, 2016, 147-154.

[9] L. E. Schrage, Linear, Integer, and Quadratic Programming with Lindo, Scientific Press, 1986.

[10] H. Siringoringo, Seri Teknik Riset Operasional. Pemrograman Linier. Penerbit Graha Ilmu. Yogyakarta. 2005.

[11] I. Syahrini, T. Sundari, T. Iskandar, V. Halfiani, S. Munzir, dan M. Ramli, Mathematical model of Parking Space unit for triangular parking area, IOP Conference Series: Materials Sciences and Engineering, 2018.

[12] W. L. Winston, Operation Research Aplications and Algorithms, International Student Fourth Edition, United States, 2004.

[13] M. Yun, Y. Lao, Y. Ma, dan X. Yang, Optimization model on scale of public parking lot considering parking behavior, The Eighth International Conference of Chinese Logistics and Transportation Professionals, 2008. 